\title{
El Niño Costero y la ocupación del territorio, cuenca del río Rímac. Caso: Chosica
}

Recibido: 22.05 .2019

Aprobado: 17.06.2019

\author{
Miguel Ángel Comeca Chuquipul, mcomecac@unmsm.edu.pe \\ Fray Masías Cruz Reyes, fcruzr@unmsm.edu.pe \\ David Mansueto Durand Castro, dduranc@unmsm.edu.pe \\ Teodoro Rojas Acosta, trojasa@unmsm.edu.pe \\ Fabriciano Máximo La Torre Ruiz, flatorrer@unmsm.edu.pe \\ Luis Miguel Comeca Ramírez, miguelcomecar@gmail.com
}

\section{RESUMEN}

En el verano de 2017 la costa norte y central del Perú soportó lluvias como no se habían registrado hace muchos años, los departamentos del norte y centro del país fueron los más afectados. En Lima se activaron el $80 \%$ de las quebradas identificadas, produciéndose huaicos e inundaciones que afectaron a los poblados de Chosica, Huachipa, Carapongo, Cajamarquilla, Santa Eulalia, Campoy, entre otros, todos ellos localizados en la cuenca del río Rímac. La ocurrencia de este fenómeno ha sido considerado atípico por su magnitud y su imprevista ocurrencia, por lo que el Comité Multisectorial encargado del estudio de este fenómeno (ENFEN) lo denominó «El Niño Costero». Este fenómeno natural generó desastres como la destrucción de viviendas, vías terrestres, puentes, colegios y otras infraestructuras, sobre todo en los poblados asentados en zonas vulnerables. En este contexto la presente investigación pretende explicar las características e impactos de este fenómeno y su relación con la ocupación del territorio por parte de la población en zonas de riesgo, como el lecho y terrazas inundables de las quebradas y el río Rímac, en el poblado de Chosica ubicado en su cuenca media.

Palabras Clave: El Niño Costero; cuenca; río Rímac; territorio.

\section{El Niño Costero and occupation of the territory, Rimac river basin. Case: Chosica}

\begin{abstract}
In the summer of 2017 the north and central coast of Peru, endured rains as they had not been registered for many years, the departments of the north and center of the country were the most affected. In Lima, $80 \%$ of the identified streams were activated, causing mudslides and floods that affected the towns of Chosica, Huachipa, Carapongo, Cajamarquilla, Santa Eulalia, Campoy, among others, all located in the Rímac river basin. The occurrence of this phenomenon has been considered atypical by its magnitude and its improvised occurrence, for which the Multisectorial Committee in charge of the study of this phenomenon (ENFEN) called it «El Niño Costero». This natural phenomenon generated disasters such as the destruction of homes, land roads, bridges, schools and other infrastructure, especially in towns located in vulnerable areas. In this context, this research aims to explain the characteristics and impacts of this phenomenon and how it relates to the occupation of the territory by the population in risk areas, such as the bed and flooded terraces of the streams and the Rímac river, in the Chosica town located in its middle basin.
\end{abstract}

KeYwords: El Niño Costero; basin; Rimac river; territory. 


\section{Introducción}

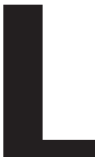

a presente investigación toma como ámbito la ciudad de Chosica, donde los efectos del fenómeno de «El Niño Costero» se manifestaron mediante la inundación de viviendas ubicadas en las márgenes vulnerables del río Rímac y los efectos destructivos producidos por huaicos y deslizamientos en los poblados asentados en el cauce y márgenes de las quebradas tributarias localizadas principalmente en la margen derecha del río, tales como Quirio, Pedregal, Libertad, Carossio, Rayo del Sol, entre otros (ver figura 1).

El objetivo central de esta investigación es dar explicación a la relación que existe entre la ocurrencia del fenómeno y sus efectos con la ocupación del territorio por parte de la población, para lo cual abordamos aspectos relacionados a la dimensión física, social, económica y política, expresados en la organización de la población, intereses políticos inmersos, conflictos de límites territoriales, flujos demográficos, informalidad en la ocupación del territorio, respuestas y rol de los organismos públicos competentes. Consideramos que los efectos de la ocurrencia de este fenómeno son mayores debido a la ocupación informal del territorio en zonas vulnerables como el lecho y áreas adyacentes al recorrido del río y las quebradas; sin embargo, esto ha ocurrido con el aval y aprobación de las autoridades en muchas oportunidades (títulos, licencias), como es el caso de Chosica.

\section{Fundamentación conceptual}

\section{Huaico o lloclla}

Existen muchas definiciones de huaicos o llocllas, aquí daremos una que en nuestra consideración orienta el presente trabajo. Los huaicos o llocllas son fenómenos de evacuación de material sólido de las cuencas por escorrentía hídrica superficial como consecuencia inmediata de lluvias violentas (aguaceros) que se reciben en las cuencas de recepción. La intensidad y magnitud de la escorrentía hídrica superficial, que posteriormente puede transformarse en huaicos o llocllas, con frecuencia puede incrementarse debido a los siguientes factores: (a) La intensidad y volumen de las lluvias. (b) La energía de las formas y pendiente del relieve. (c) La naturaleza mineral del sustrato ro-

\section{Figura 1}

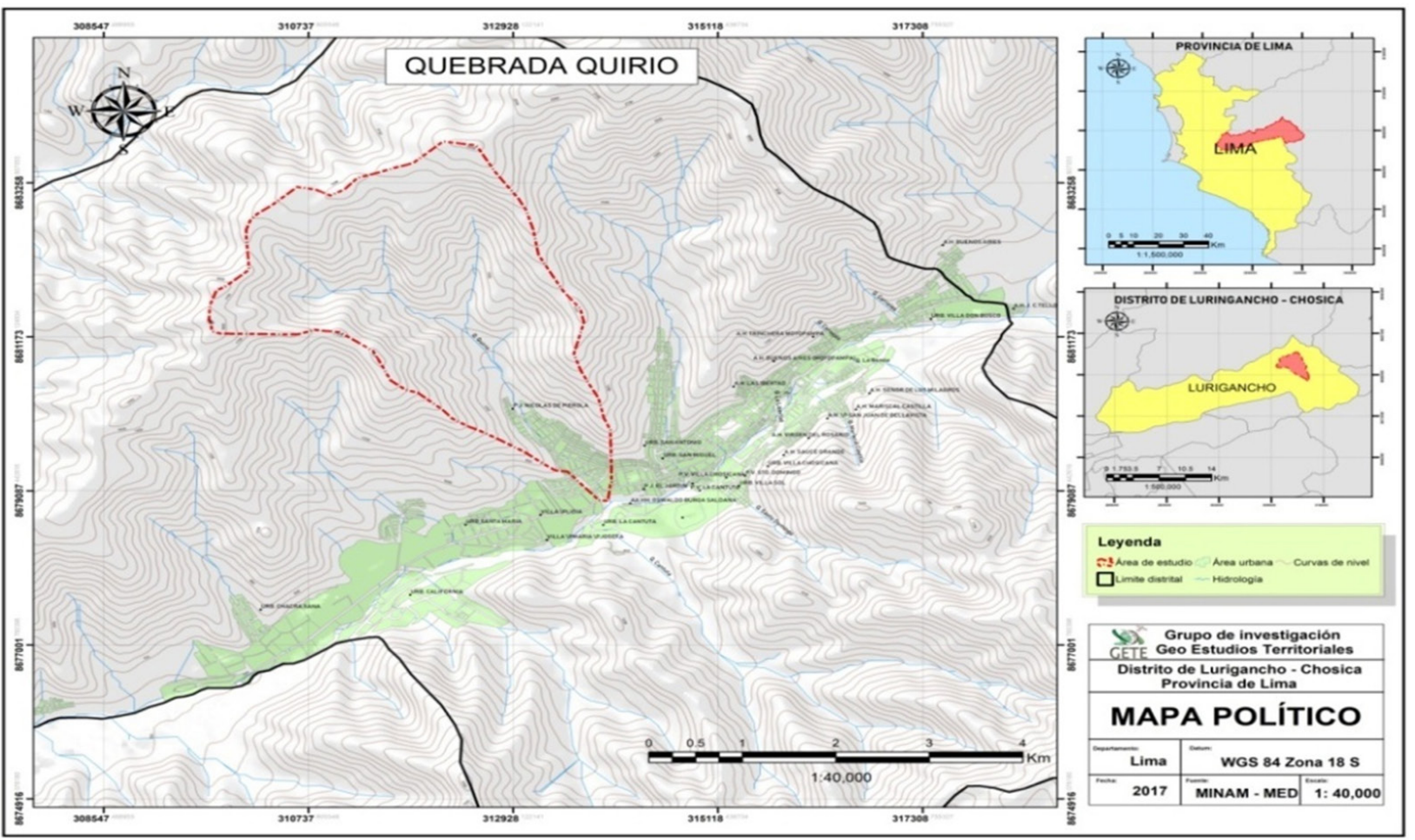


coso expuesto. (d) La abundancia de material suelto en superficie, resultante en este caso de generalizados procesos de termoclastismo intenso. (e) La falta de cobertura vegetal protectora del suelo frente a los agentes erosivos. (f) Las fuertes pendientes de las vertientes y laderas altas de la cuenca de recepción. (g) La forma y extensión de la cuenca, que tiene que ver con la capacidad de recolección de las aguas de lluvia. (h) Las características de su red de avenamiento. (i) Las condiciones y características del canal principal de evacuación del material torrencial. (j) Los factores antrópicos, como: las malas prácticas de uso del suelo, el sobrepastoreo, la quema, el tránsito intenso, etc. Estos factores dan como resultado espacios diferenciados que condicionan y pueden facilitar la frecuencia de la ocurrencia de huaicos o llapanas.

\section{Clima}

Es un factor importante que actúa directamente sobre la mayor parte de los factores generadores de eventos naturales, algunas de las principales consecuencias de esta influencia son la ocurrencia de las lluvias, su volumen, intensidad, el ritmo y la distribución espacial, en suma responsable del régimen hidrológico de los ríos costeros; además responsable de la activación de los huaicos propios de las cuencas torrenciales; sin embargo, es necesario diferenciarlos de los fenómenos relacionados con los generados por «El Niño Costero», que está referido a las lluvias que ocurren como consecuencia de mayores temperaturas superficiales del mar (TSM) registradas en proximidades al litoral.

En el área de la presente investigación, tenemos la presencia de dos tipos climáticos principales: un clima seco o desértico y un clima de estepa con lluvias de verano y seco en invierno.

El área con clima seco o desértico, cuya característica más notable es el déficit extremo de agua debido a la falta de lluvias a lo largo del año, excepto en las épocas que corresponden a la ocurrencia de los fenómenos de El Niño. Este clima seco, adquiere sus características dominantes debido al dinamismo y persistencia de los vientos relativamente fríos para la latitud, generados por el Centro de Altas Subtropicales del Pacífico Sur (CASTPS), que en la época de invierno (abril a diciembre) llegan aunque disminuidos en su velocidad, pero con cierta persis- tencia hasta $\operatorname{los} 4^{\circ}$ latitud sur, transmitiendo condiciones de presión y temperatura que generan gran estabilidad atmosférica inclusive con masas de aire subsidentes, que tienden a generar desecamiento, alejando la probabilidad de que la humedad del aire alcance la saturación por disminución de la temperatura, por lo tanto, las condiciones de producción de lluvias no se producirán mientras este proceso físico actúe.

Otro aspecto que complementa el clima seco o desértico, se inicia a fines de diciembre y se produce debido a una inhibición del CASTPS, ya que en la época se desplaza con dirección hacia el sur del trópico, permitiendo al mismo tiempo, el avance hacia más al sur del paralelo $4^{\circ}$ latitud sur de masas cálidas del agua de mar y de masas de aire asociadas a la convergencia intertropical (CIT) húmedas e inestables productoras de lluvias. Cuando en el verano austral esta situación se alterna a raíz del desplazamiento del CASTPS hacia el sur propicia el avance de la zona de convergencia intertropical acentuado por un incremento notable de las TSM en el litoral típico en diciembre, el proceso de producción de lluvias es positivo, lo que caracterizó al fenómeno de El Niño, que en el 2017 se pudo observar recién en el mes de marzo afectando el litoral norte y centro de nuestra faja costera, por lo que se le llamó «El Nińo Costero". Las consecuencias de este fenómeno se asocian también con la producción de lluvias intensas de verano en el norte interandino del territorio peruano incluyendo los Andes que gradualmente van disminuyendo de intensidad hacia el centro y el sur del país.

La altitud que alcanza el piso de este estrato nuboso de gran estabilidad, que puede alcanzar niveles algo por encima de Chosica, varía localmente por factores morfológicos, orográficos, de exposición tanto a los vientos del sur y sureste como a la exposición solar que disipa las nubes del piso que entran en contacto con el terreno, lo que es común en el invierno, trae como efecto una acentuada humectación que facilita el proceso de disgregación granular denominado termoclastismo y el rocío nocturno que puede generar la vegetación herbácea efímera de las lomas.

Las condiciones climáticas tienden a variaciones diarias, estacionales e interanuales notables cuya cuantificación debe hacerse a través de las estaciones meteorológicas. 
El área con clima de estepa, caracterizada por la ocurrencia de lluvias estacionales (diciembre a marzo) que alterna con una estación seca (abril a noviembre), se trata de un área en donde se dan condiciones secas de desierto durante el invierno y lluviosas en el verano del mismo año. En esta situación el rol morfológico de la escorrentía hídrica se acrecienta al verse favorecida por la falta de cobertura vegetal que florece durante la estación del verano lluvioso corto, y que muere muy pronto debido a la estación seca de invierno largo, además de acentuarse un notable déficit de agua en el medio. En esta área no se cuenta con información meteorológica, situación que nos obliga a plantear algunos aspectos en relación con el clima basados en nuestras observaciones directas en el campo del área de estudio.

\section{Dinámica torrencial}

El agente principal en la generación de huaicos o llapanas es la escorrentía hídrica superficial que se inicia con la morfodinámica pluvial, el impacto de las gotas de la lluvia que van dejando microhoyos y movilizando las primeras partículas más finas del suelo seco y polvoroso para luego dar paso, al inicio, a la escorrentía hídrica difusa y, si el suelo es arenoso y poroso, luego de su saturación, se inicia la escorrentía laminar, luego tiende a concentrarse en pequeños surcos, cuyas confluencias incrementan el volumen de la escorrentía concentrada, los que a su vez confluyen dando origen a zanjas que, de igual manera, se concentran confluyendo en cárcavas, para luego formar canales por los que drenan las lavas torrenciales y confluyen en un canal principal que es el encargado de evacuar la lava torrencial y depositarlo en el cono de deyección. En la cuenca torrencial conviene distinguir la morfodinámica de tres sectores: la cuenca de recepción, el canal principal de evacuación del flujo torrencial y el cono de deyección.

La cuenca de recepción es la zona de captación y de aporte de material sólido e hídrico. En el canal principal, aun cuando hay erosión por escavado y socavamiento, predominan el transporte de material torrencial y el cono de deyección que es el sector donde se produce el abandono o depósito de los materiales transportados.

\section{Fenómeno de «El Niño Costero» 2017}

La ocurrencia de «El Nińo Costero», en el verano del 2017, ha significado una violenta e inusual manifestación climática en la costa peruana, por ende, también sus efectos destructivos se han manifestado en la cuenca media del río Rímac, específicamente en la localidad de Chosica ámbito de nuestra investigación. Este fenómeno se define como la elevación anómala y persistente, de forma abrupta, de la temperatura superficial del mar en el Océano Pacífico adyacente a la costa del norte del Perú y de Ecuador (ENFEN, 2017); su ocurrencia está asociada a alteraciones a gran escala del campo de presión atmosférica, vientos y la circulación oceánica en el Pacífico ecuatorial, así como a alteraciones en la circulación atmosférica sobre el Pacífico sudeste; se manifiesta durante los meses de enero a marzo cuando, debido a su magnitud y persistencia, provoca la generación de intensas precipitaciones en las zonas de altitudes medias y bajas de la costa, accionado por la evaporación de la capa superficial del agua, transporte del aire húmedo cálido del mar a la costa y condensación durante el ascenso topográfico de la masa de aire.

En suma, El Niño Costero se caracteriza por el debilitamiento de los vientos alisios y la presencia de los vientos del norte en la costa norte y central peruana, el incremento brusco de la temperatura del mar, los niveles de precipitación extremos y el calentamiento superficial del mar. Según el IMARPE la temperatura máxima de las aguas superficiales del mar alcanzó en la costa norte frente a Piura los $29^{\circ} \mathrm{C}$ (ENFEN 2017).

Por sus impactos asociados a las lluvias e inundaciones El Niño Costero se puede considerar como el tercer fenómeno de El Niño más intenso en los últimos cien años para el Perú (ENFEN 2017). Considerando la magnitud de ocurrencia del fenómeno ocurrido ese año, es comparable con dos eventos ocurridos en los años 1925 y 1987 que generaron similares efectos destructivos, sobre todo en Chosica.

Por otro lado, si se toma en consideración el caudal del río es comparable según referencias históricas a la máxima avenida del río Rímac que se dio en marzo de 1923 con un caudal de $178 \mathrm{~m}^{3}$ y los $100 \mathrm{~m}^{3}$ alcanzados el 15 de febrero de 1925 (O'Connor, 1989). Adicionalmente una característica que coadyuva lo manifestado sobre El Niño Costero, en cuanto a su dinamización, es la acción antrópica global reflejado en el cambio climático mundial; así como 
la acción antrópica local manifestada en la creciente ocupación informal de la población y la construcción de sus viviendas en el lecho de quebradas y ríos, así como en las laderas empinadas compuesto generalmente de material inestable.

\section{Metodología}

La presente investigación toma como objeto un aspecto de la realidad, es decir, un ámbito territorial definido externo al sujeto; lo cual nos permitió abordarlo temáticamente con una mirada y contenido geográfico. La tipología de investigación que se ha definido es descriptiva, explicativa y correlacional.

Con la finalidad de hacer un estudio específico y detallado de la problemática abordada por esta investigación, se definió como muestra la zona de muy alto riesgo del asentamiento poblacional Nicolás de Piérola, emplazado en el cauce y margen de la quebrada de Quirio, donde la población ocupó y edificó sus viviendas incluso estrangulando el cauce mismo de la quebrada.

El estudio de esta zona crítica sintetiza la manera como se ha dado la ocupación del territorio de Chosica de manera desordenada e informal, carente de una visión de ciudad planificada, situación que se repite en las otras quebradas y la terraza baja del río Rímac.

El desarrollo de la investigación se inició con la recolección de información temática y cartográfica, luego se elaboró los mapas base con el fin de clasificar y analizar la información, en seguida se identificó los aspectos físico-naturales, socioeconómicos y políticos, apoyados con la revisión de material documental; luego se complementó con trabajo de campo mediante la observación, evaluación, contrastación y ejecución de encuestas.

\section{Resultados}

\subsection{Características generales del distrito de Lurigancho-Chosica}

El distrito de Lurigancho-Chosica fue creado el 21 de enero de 1825 por Bolívar, luego el parlamento ratifica su creación el 2 de enero de 1857, posterior- mente por ley del 9 de noviembre de 1896 se traslada la capital del distrito a Chosica (PDLC, 20132025). Se ubica en la parte este del departamento de Lima, su capital se asienta en el curso inferior del río Rímac, en ambas márgenes; sin embargo, la mayor parte de su territorio distrital se localiza en la margen derecha del río, la altitud promedio de la ciudad es de $860 \mathrm{msnm}$ que corresponde a la región natural yunga, posee un clima agradable, benigno y soleado. El emplazamiento urbano de Chosica, objeto de la presente investigación, se da sobre tres niveles de terrazas de depósito fluvial y aluvial relativamente estable en ambas márgenes, es una zona angosta de valle rodeada de cerros encañonados, sometido a continuos procesos de erosión y sedimentación debido a los continuos embates de avenidas y su secuela de inundaciones en las zonas cercanas y bajas del río (O’Connor, 1989). Aquí se identifican alrededor de 12 quebradas tributarias del río Rímac en ambas márgenes, secas a lo largo del año, activas y torrenciales en los meses de verano.

\section{Crecimiento urbano}

En sus inicios la Chosica antigua se ubicó en la margen izquierda del río, posiblemente por su menor vulnerabilidad ante la activación de las quebradas de la margen derecha. Sin embargo, según el historiador Walter Stubbs, en 1894, por gestión personal de Emilio del Solar, se edifica en la propiedad de la hacienda Chosica, en la margen derecha, la nueva urbanización, posteriormente en 1896 pasa a convertirse en capital del distrito de Lurigancho. Su crecimiento urbano fue lento, empezando a acelerarse desde la década de los 40, se inicia con la expansión hacia Ricardo Palma y la aparición de los primeros asentamientos poblacionales en las laderas y riberas.

En su evolución demográfica, según datos censales del INEI para 1940, Chosica contaba con 4420 habitantes; sin embargo, a partir de la década de los 70 empieza el poblamiento masivo en áreas aledañas a las quebradas, alcanzando 47873 pobladores en 1972, época cuando se produce un silencio de huaicos por lo que la población subestima los peligros y empieza a ocupar incluso el cauce natural de las quebradas. Hay un caso para destacar, en 1973 la Municipalidad de Lima emite una resolución aprobando la lotización definitiva de San Antonio 
Figura 2

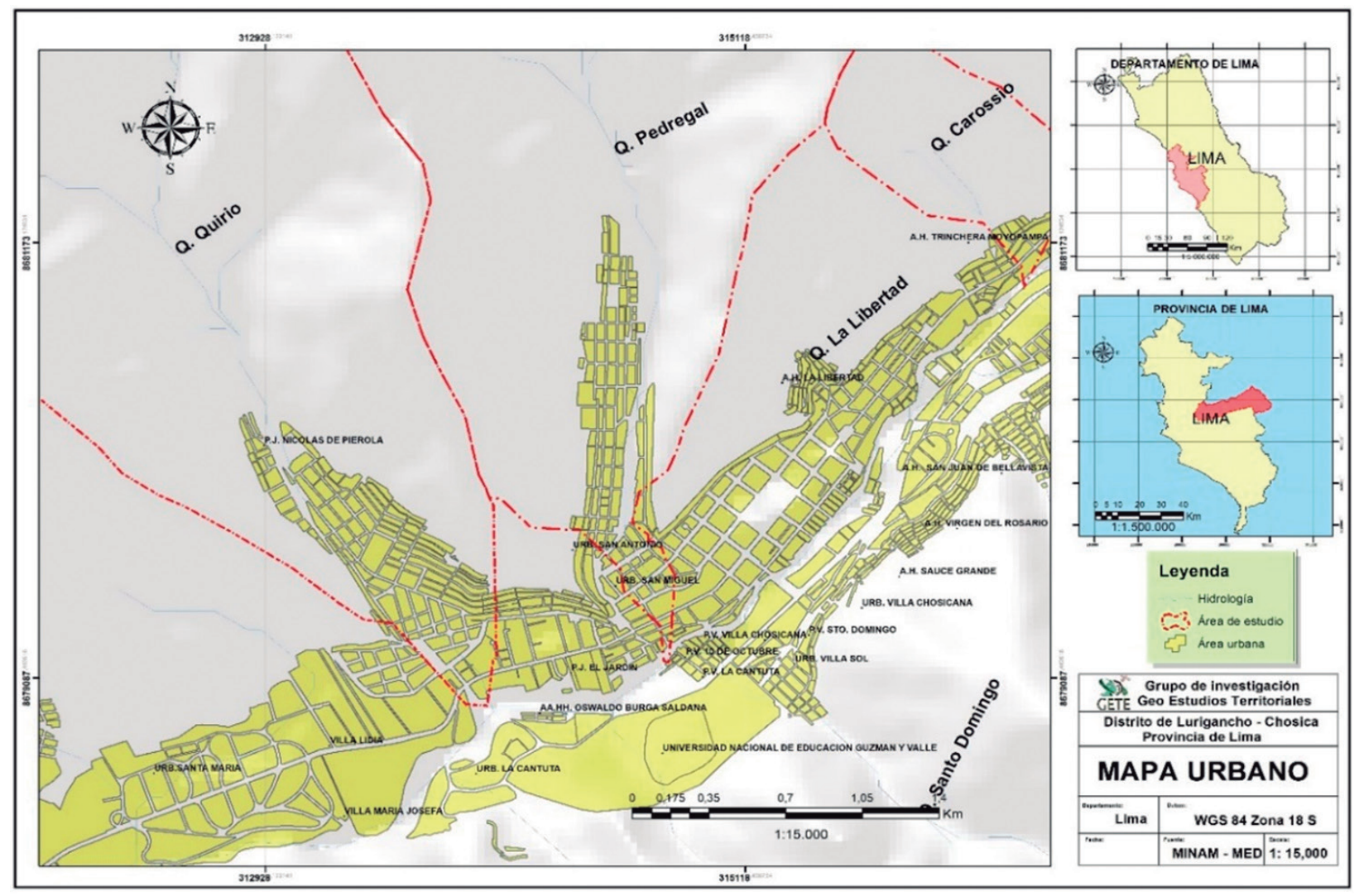

de Pedregal Alto (Pérez 2009). En el año 1981 la población de Chosica representa el $77 \%$ de la población del distrito de Lurigancho; posteriormente, según el censo de 2007, la población del distrito de Lurigancho-Chosica asciende a 169359 habitantes y la población proyectada al 2015 era de 218976 personas (INEI). En la actualidad sigue el incremento de la población en áreas que presentan un alto grado de vulnerabilidad, donde han construido sus viviendas. Hay asentamientos poblacionales que están emplazados en el lecho natural de las quebradas o en las laderas de alta pendiente y material inestable (ver figura 2).

\subsection{Estudio específico de Nicolás de Piérola}

Con la finalidad de hacer un análisis específico y detallado del área de estudio se definió como muestra la zona de muy alto riesgo del asentamiento poblacional Nicolás de Piérola, donde la población está asentada en las márgenes aledañas a la quebrada de Quirio y en algunas zonas en el cauce de la misma. La edificación de viviendas se ha dado de manera desordenada e in- formal, carente de una visión de ciudad planificada, situación que se repite en las otras quebradas y terraza baja del río Rímac. A continuación, se presenta el estudio detallado de esta zona crítica.

\section{a. Caracterización del área de estudio}

El asentamiento poblacional Nicolás de Piérola se encuentra ubicado en la margen derecha del río Rímac, forma parte de la ciudad de Chosica, se extiende en las márgenes y parte del lecho de la quebrada de Quirio, tributario del río Rímac. Este sector sufrió el mayor impacto por la ocurrencia del fenómeno El Nińo Costero 2017, los vestigios aún se mantienen a la vista, constatando la inacción por parte de las entidades públicas competentes y de la población misma; se observó en las visitas efectuadas, débiles y aislados esfuerzos en acciones que les permita desarrollar sus actividades cotidianas referidas al acceso, seguridad y restablecimiento de los servicios afectados; todo esto se traduce en la ausencia del concepto de planeamiento urbano y de resiliencia frente a los fenómenos naturales (ver figuras 3 y 4 ). 
Figura 3

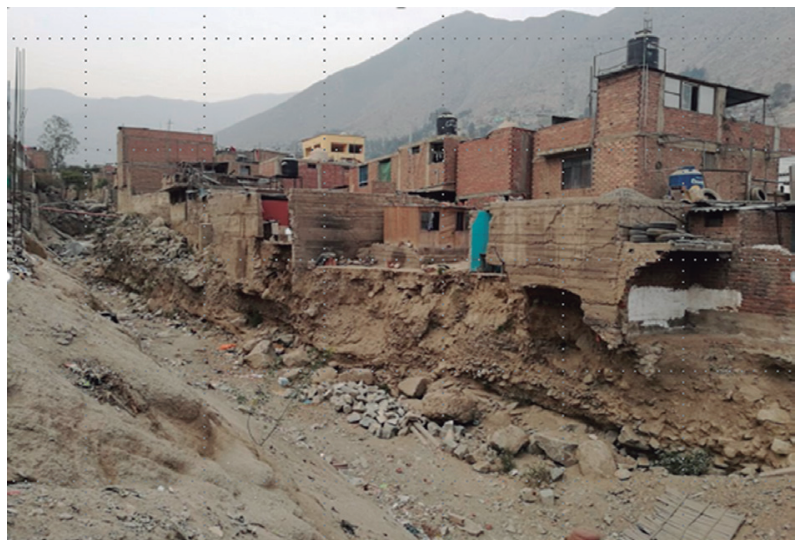

\section{b. Ocupación del territorio}

Nicolás de Piérola está emplazado sobre terrazas fluviales y aluviales de pendiente pronunciada y corta longitud (de 3 a $4 \mathrm{~km}$ ). Las cumbres que lo circundan presentan igualmente fuertes pendientes, con la presencia de cárcavas que representan una amenaza; factores y procesos tales como geología, topografía, geodinámica externa, cursos de drenaje, altitud y la misma actividad humana han influido en la confi-
Figura 4

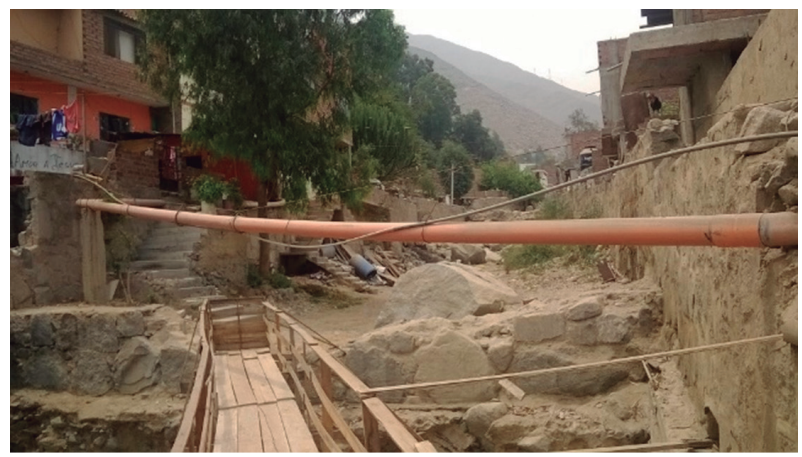

guración física actual de la subcuenca de la quebrada Quirio.

Este sector está considerado con un alto grado de vulnerabilidad y tiene restricciones para fines de ocupación urbana (INDECI 1985). Sin embargo, se edificaron viviendas en ambas márgenes y en el cauce de la quebrada; en la parte baja, antes de la ocurrencia del huaico, la calle Micaela Bastidas era una vía peatonal, luego de activado el torrente ha sido destruida (ver figura 5). Se observó que la margen izquierda de la quebrada es un espacio de alto riesgo por el componente de material coluvial y de relleno, mientras

Figura 5

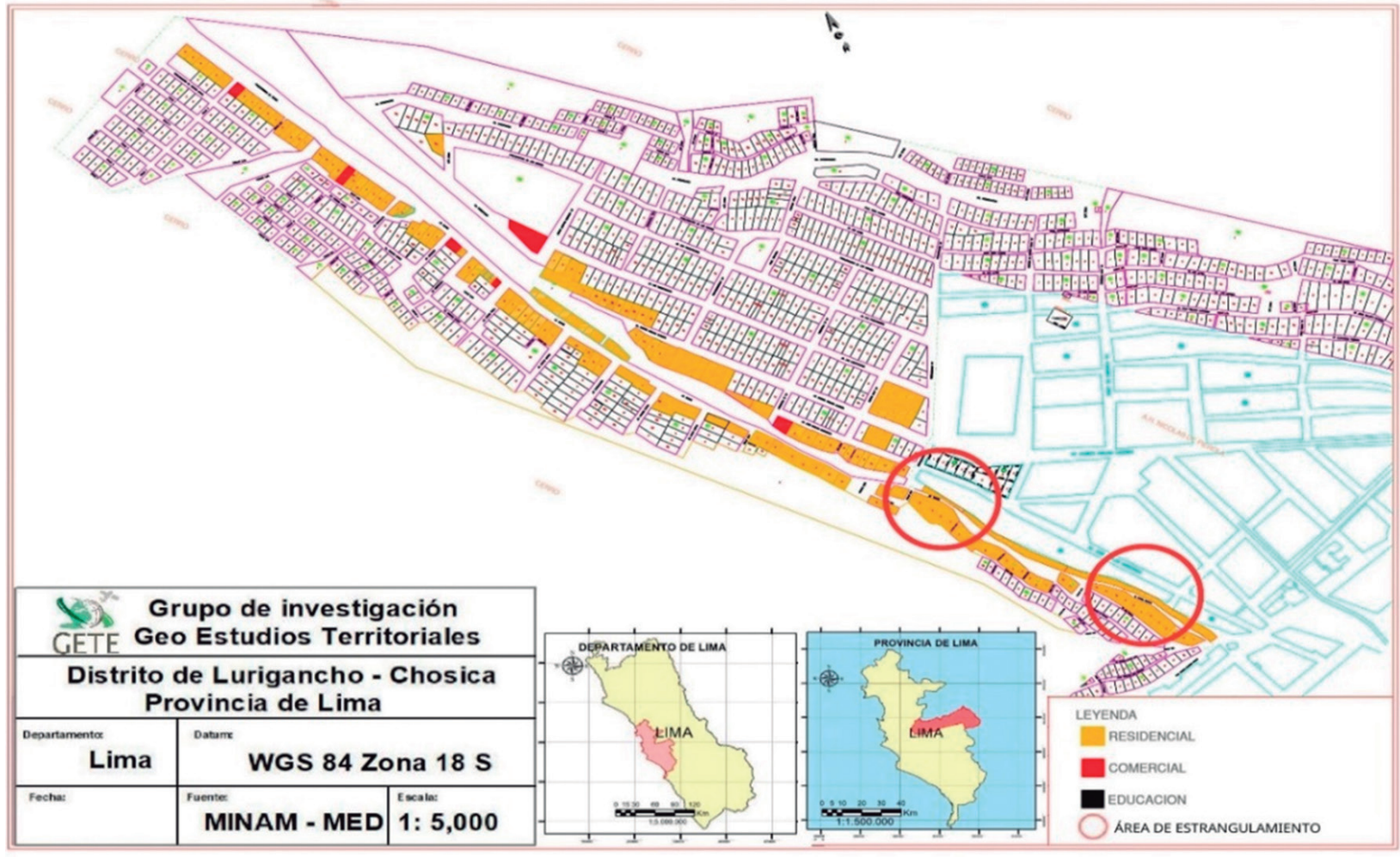


que la margen derecha es de mayor estabilidad por su constitución rocosa subyacente.

\section{c. Clasificación de uso del suelo}

Para determinar el uso actual del suelo urbano de esta zona de riesgo se llevó a cabo el levantamiento de información de campo sobre el uso del suelo, mediante las encuestas, clasificándose en tres tipos de uso: el residencial, el comercial y equipamiento urbano.

GRÁFICO 1

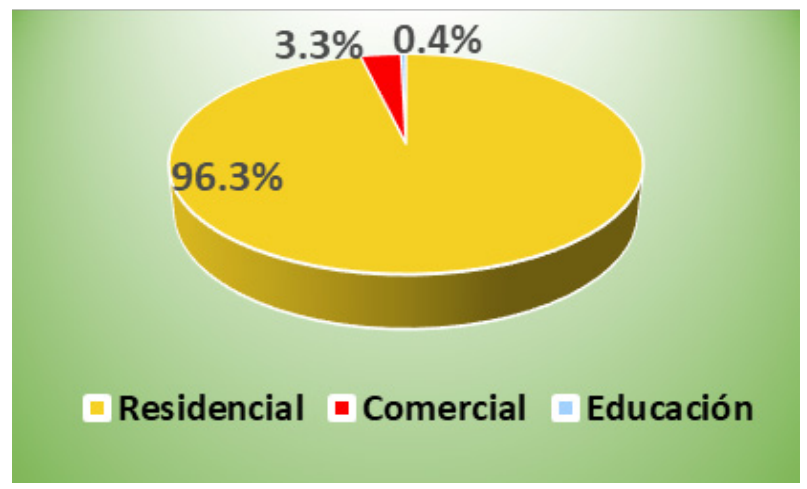

GRÁFICO 2

\begin{tabular}{|l|r|r|}
\hline \multicolumn{1}{|c|}{ Uso del suelo } & \multicolumn{1}{c|}{ N. ${ }^{\circ}$ Viv. } & \multicolumn{1}{c|}{$\%$} \\
\hline Residencial & 233 & 96.3 \\
\hline Comercial & 8 & 3.3 \\
\hline Educación & 1 & 0.4 \\
\hline TOTAL & 242 & 100,00 \\
\hline
\end{tabular}

De acuerdo con el levantamiento de usos del suelo, tal como se observa en el cuadro y correspondiente gráfico, el uso predominante es el residencial equivalente a un $96 \%$; luego un $3.3 \%$ corresponde al uso comercial y menos del $1 \%$ a educación (ver gráficos 1 y 2).

\section{Características de la vivienda}

\section{Material de construcción}

De acuerdo con el gráfico adjunto el material que predomina en las construcciones es el ladrillo que representa el 93\% del total de las viviendas y casi todas se han construido sin ninguna orientación ni apoyo técnico.

\section{GrÁFICO 3}

Material de construcción

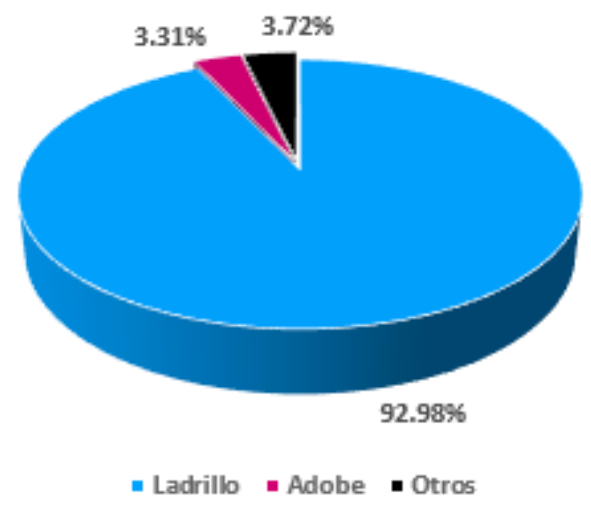

GrÁFICO 4

\begin{tabular}{|l|r|r|}
\hline & Material de & \multicolumn{1}{c|}{ Porcentaje } \\
\hline Ladrillo & 225 & 92.98 \\
\hline Adobe & 8 & 3.31 \\
\hline Otros & 9 & 3.72 \\
\hline
\end{tabular}

Esta situación demuestra la falta de control urbano por parte de la entidad correspondiente, al permitírseles la autoconstrucción con material noble en una zona de alto riesgo (ver gráficos 3 y 4). Asimismo, se han identificado construcciones en material de adobe $(3 \%)$ y otros materiales que representan casi el $4 \%$.

\section{Altura de la construcción}

De acuerdo con la información levantada el 52.89\% de las construcciones son de un solo piso, de dos pisos

\section{Gráfico 5}

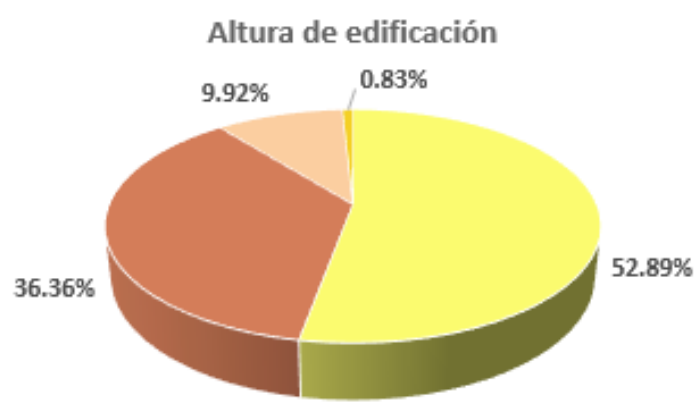

Un piso - Dos pisos $\mid$ Tres pisos $\mid$ Cuatro pisos 
representan el $36.36 \%$, de tres pisos alcanzan $10 \%$ y las de cuatro pisos llegan apenas a $0.83 \%$ (ver gráficos 5 y 6). Cabe destacar que las viviendas de dos pisos a más representan cerca del $48 \%$, las mismas que han sido construidas, de acuerdo con lo observado y por la versión de los pobladores, sin la participación de un profesional ni asistencia técnica, por lo que casi todas estas viviendas no cuentan con estructuras adecuadas, resultando vulnerables ante un fenómeno natural.

\section{Estado de la construcción}

De acuerdo con la información recogida in situ, aproximadamente el $20 \%$ de las construcciones se encuentran en buen estado de conservación. El 58\% de las construcciones se encuentran en regular estado de conservación y el $21 \%$ se encuentra en malas condiciones de conservación (ver gráficos 7 y 8). Estos porcentajes corroboran el estado de vulnerabilidad en que se encuentran físicamente las construcciones del sector estudiado, ya que no solo están mal construidas sino que no tienen mantenimiento.

\section{GRÁFICO 7 \\ Estado de conservación}

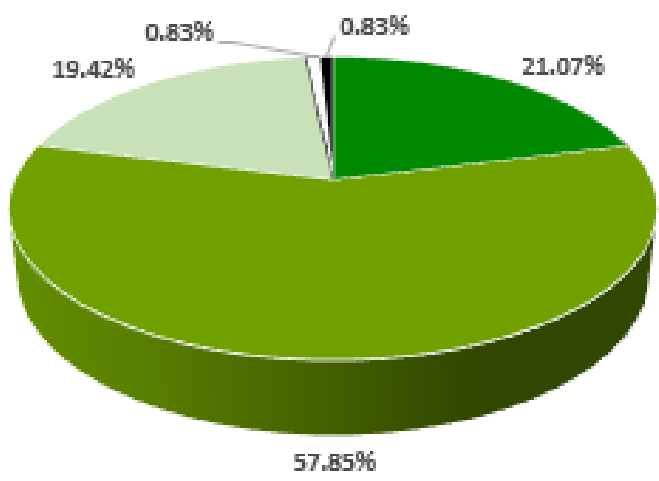

- Malo | Regular = Buena DMuybueno - Sinconstruir
GrÁfICO 7

\begin{tabular}{|l|r|r|}
\hline Estado de con & Constryc. & Porcentaje \\
\hline Malo & 51 & 21.07 \\
\hline Regular & 140 & 57.85 \\
\hline Buena & 47 & 19.42 \\
\hline Muy bueno & 2 & 0.83 \\
\hline Sin construir & 2 & 0.83 \\
\hline & 242 & \\
\hline
\end{tabular}

\section{d. Aspectos socioeconómicos}

Según la referencia del Directorio Nacional de Centros Poblados del año 1994-INEI, la población del asentamiento Nicolás de Piérola para 1993 era de 8259 habitantes y con un registro de 1660 viviendas, esta situación debe haberse incrementado en ambos casos por el avance de la expansión urbana en zonas no adecuadas-marginales y laderas de cerros, como se pudo evidenciar en las visitas efectuadas al mencionado asentamiento.

Cabe mencionar que el estudio "Análisis de la situación de salud del C. S. Nicolás de Piérola», elaborado por el Ministerio de Salud (2004), consigna algunas referencias relacionadas con la pobreza, como es el caso de la población pobre representada por un $60 \%$ y $15 \%$ en pobreza extrema. En cuanto a la población laboral en su mayoría la constituyen obreros, empleados del hogar, artesanos y ambulantes; asimismo, existe un alto nivel de desocupación y subempleo, factores que conllevan a problemas de carácter social como pandillaje, prostitución, delincuencia y drogadicción. Esta información ha sido corroborada por la misma población.

\section{e. Vulnerabilidades y resiliencia}

El asentamiento Nicolás de Piérola tiene una conformación física inestable que presenta en la plataforma superior laderas con pendientes pronunciadas, sectores erosionados, por lo mismo la población es vulnerable desde el punto de vista físico, social, económico, ambiental y político, en parte debido a la falta de una planificación adecuada. En este contexto hay dos asuntos que se deben tomar en consideración, la forma de prevenir, rehabilitar y/o reforzar al centro poblado y la infraestructura ya existente, y la forma 
de planificar las nuevas infraestructuras a la luz de los peligros actuales.

El gobierno local debe estar en primera línea en la respuesta a los desastres, el mensaje es que la resiliencia y la reducción del riesgo de desastres deben formar parte del diseño y estrategias urbanas para lograr un desarrollo sostenible. Se necesita que esta acción sea integral y con una amplia participación.

Se debe entender la resiliencia como la capacidad de la comunidad o la sociedad, expuestos a un evento natural, para resistir, absorber, adaptarse y recuperarse de sus efectos, de manera oportuna y eficaz, lo que incluye la preservación y restauración de sus componentes, estructuras y funciones básicas.

La encuesta aplicada para medir la resiliencia, basada en la preocupación de salvaguardar la vida humana y minimizar los daños a las personas, da como resultado que casi el $100 \%$ de los encuestados manifiesta estar desprotegido frente a situaciones de emergencia por parte de instituciones y organizaciones privadas y públicas, igualmente la población no está debidamente organizada para tener respuestas a situaciones de emergencia.

\section{Discusión}

\subsection{Ocupación de áreas vulnerables no aptas para la ocupación urbana}

Mediante la investigación se ha podido comprobar que la ocupación del territorio de Chosica con fines de vivienda se ha dado de manera informal y desordenada, los flujos migratorios han desbordado la respuesta del Estado para una ocupación ordenada y planificada en áreas seguras que no representen riesgos; consecuentemente han ocupado áreas inundables del río Rímac, así como en las márgenes y lechos de las quebradas tributarias presentes en Chosica, esta situación a la fecha aún continua, como la quebrada de Quirio descrita anteriormente.

A nivel de toda la urbe las áreas más vulnerables por su exposición al peligro, sobre todo a los huaicos, son los asentamientos humanos Nicolás de Piérola, San Antonio de Pedregal, San Miguel de Pedregal, Santo Domingo, Pedregal bajo, Rayitos de Sol. Por otro lado, también se puede identificar asentamientos expuestos a deslizamientos o desprendimientos de rocas que se ubican en laderas inestables, así como asentamientos humanos asentados en la terraza baja del río que se encuentran expuestos a inundaciones. Un dato que corrobora esta situación es que el 67\% de la población, aproximadamente unos 48 mil habitantes, que representa el $41 \%$ del área urbana de Chosica, se encuentra en situación de riesgo alto (PDLC, 2013-2025).

En función a la acción antrópica, es decir, el asentamiento de la población y su exposición al peligro como inundaciones, huaicos, deslizamientos y derrumbes, y teniendo como referencia la propuesta del Plan de Desarrollo Local Concertado de Chosica, se identifican tres zonas con niveles de vulnerabilidad:

Zona de riesgo muy alto. Comprende la parte del área central, entre las calles Arequipa y Arica desde la Av. 28 de Julio hasta el A. H. La Libertad; las áreas pobladas ubicadas a lo largo de las quebradas El Pedregal y Quirio: AA. HH. Mariscal Castilla y Santo Domingo; zona de la Asociación María Auxiliadora y parte de los asentamientos colindantes con las quebradas Corrales, Carossio y La Cantuta; asimismo, las riberas del río Rímac.

Estos emplazamientos, mayormente ubicados en los mismos cauces de quebradas y cárcavas de fuerte pendiente que están ocupadas, son altamente vulnerables por su ubicación, además que las características constructivas de las viviendas y el estado de conservación de las edificaciones las hace poco seguras ante la ocurrencia de cualquier evento (ver figura 6).

Zona de riesgo alto. En Chosica se tienen demarcadas como zonas de peligro alto las laderas de las principales quebradas y la llanura de inundación, que actualmente en su mayor parte se encuentran ocupadas por viviendas y el comercio.

Zona de riesgo medio. Esta zona corresponde a las laderas de las quebradas y las partes intermedias de las laderas que colindan con la ciudad, además del área restante de la ciudad de Chosica.

Sin embargo, los sectores preponderantemente críticos resultan la quebrada Quirio (19\% de la población) y la quebrada Pedregal (13\% de la población), debido a que se encuentra en riesgo un mayor número de vidas humanas, así como por presentar los peligros más violentos y de mayor desastre registrados en la cuenca del río Rímac durante los numerosos fenómenos de El Niño ocurridos y sobre todo el último de 2017. 
Figura 6

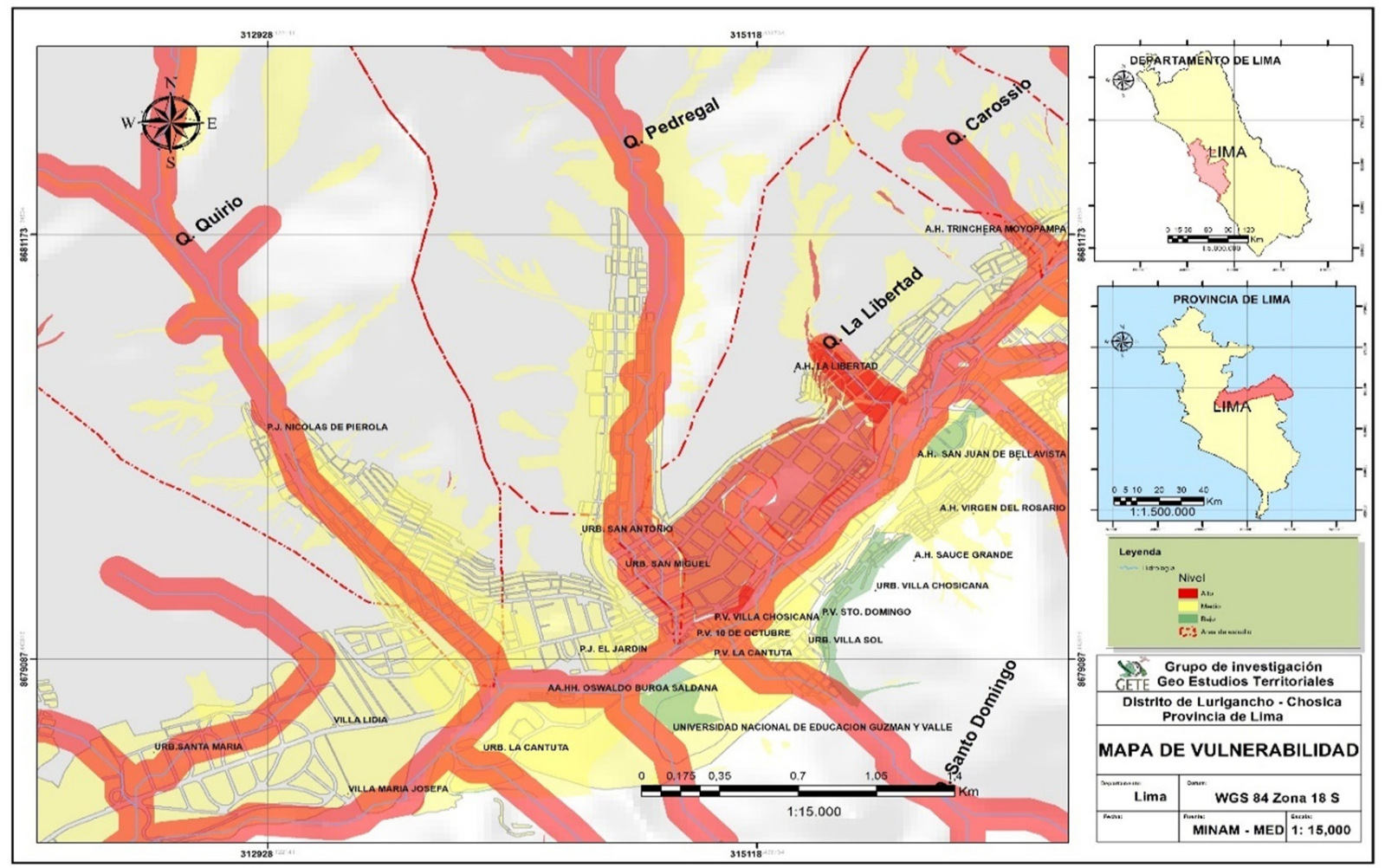

\subsection{Factores sociales que se relacionan con la ocupación urbana en zonas de riesgo}

La ocupación del territorio de Chosica con fines de vivienda, de manera informal y desordenada, se relaciona con las condiciones de ocupación precaria en algunos sectores, debido a la falta de recursos económicos de sus pobladores; la pobreza está presente sobre todo en los que ocupan las áreas marginales y periféricas o más empinadas, alejados de los servicios básicos como el agua y la electricidad, por ello no es extraño aquí la presencia de los traficantes de terrenos ante la inexistente acción del Estado.

Se ha podido constatar, mediante trabajo de campo, que existe un bajo nivel de organización; el desinterés está presente salvo cuando se da la ocurrencia del fenómeno natural, entonces la población se agrupa por sectores representados por delegados a lo largo de las quebradas, además de tener un representante a nivel de todo el asentamiento poblacional como es el caso de Nicolás de Piérola y San Antonio de Pedregal.

A nivel de presencia del Estado u organizaciones de poder, en el ámbito de la investigación se ha cons- tatado la presencia de la Municipalidad de Chosica de manera directa o a través de una agencia municipal en las poblaciones asentadas en las quebradas; asimismo, hay presencia de la Municipalidad de San Antonio a través de la agencia municipal del Centro Poblado Nicolás de Piérola, sobre todo en la parte media y alta de las quebradas de Quirio, Pedregal, Carosio y las otras quebradas ubicadas en la margen derecha del río Rímac; por otro lado, como organización social, la comunidad de Jicamarca también está presente.

Esta situación tiene una relación directa con la existencia de un conflicto limítrofe entre el distrito de Lurigancho-Chosica y el distrito de San Antonio, que de una manera u otra afecta la cohesión organizacional de los asentamientos poblacionales inmersos en esta área de estudio, tal como se ha podido comprobar por las discrepancias existentes en la organización de la parte baja, media y alta de las quebradas. Esta situación genera un vacío administrativo del territorio, que perjudica en la atención de servicios y obligaciones por parte de las municipalidades hacia la población. La existencia de estos vacíos son aprovechados por los traficantes de terrenos que actúan 
al margen de la ley, viéndose perjudicada la propia población.

\section{Comunidad versus distrito}

En el contexto del crecimiento urbano-poblacional que experimentaba la capital de la república desde mediados del siglo $\mathrm{xx}$, se experimenta una presión continua de familias emigrantes que buscaban lugares donde habitar, algunas de ellas tomaron posesión en la margen derecha del río Rímac en terrenos de la comunidad de Jicamarca. Ante esta situación, para mantener el control territorial, la comunidad decide asimilar a esta nueva población dándole el estatus de "comuneros asimilados», mediante los anexos comunales a los cuales les otorgó autorizaciones de usufructo (Cáceres, La Torre y Ccente 2005).

Así, entre 1948 y 1956, los dirigentes de la comunidad de Jicamarca crearon los anexos de Pedregal, Nicolás de Piérola y La Perla de Jicamarca cerca de la capital distrital de Chosica. Entre 1956 y 1962 se crearon otros anexos como sierra limeńa, Micaela Bastidas, Yanocoto. Posteriormente la formación de anexos fue recesada hasta mediados de la década de los sesenta, para dar paso a la creación de barriadas (1968-1975), período que comprende el gobierno militar. En esta etapa Nicolás de Piérola y San Antonio de Pedregal decidieron eximirse de pertenecer a la comunidad y se constituyeron como "pueblos jóvenes». Entre el 80 y 90 se crearon la mitad de los anexos de Jicamarca afectando seriamente la organización territorial y política de la comunidad campesina. Entre el 80 y 85 se gesta la creación de los anexos Vallecito, El Algarrobo, Río Seco. En este contexto se van formando organizaciones ajenas a la comunidad como las asociaciones de viviendas que a diferencia de la comunidad ofrecen titulación de las tierras que ocupan, es decir las tierras divididas como lotes de terreno destinado a vivienda. A inicios de los 90 Jicamarca ya contaba con 24 anexos (Gutiérrez Galindo 1998).

Los dirigentes y personas de los poblados que inicialmente fueron denominados anexos, como es el caso de Pedregal y Nicolás de Piérola, estaban conformados por una población mejor informada, en su mayoría con educación secundaria y superior, situación diferente a los anexos andinos o más alejados. Tanto Pedregal como Nicolás de Piérola, ubicados cerca de la ciudad de Chosica, de una manera u otra tenían mayor acceso a los servicios que ofrece esta, cosa que no sucede con San Antonio. La población de estos nuevos anexos se identifica más con su vivienda; es decir, se vuelve urbana, se distritaliza, perdiendo paulatinamente la identificación como comunero; esto tiene como consecuencia el desencuentro entre la comunidad matriz y los anexos, entre los comuneros originarios de Jicamarca y los nuevos anexos compuestos de población foránea. Sus objetivos ya son diferentes, mientras los comuneros tienen como meta central la recuperación de tierras comunales sin poner atención a promover proyectos para la infraestructura vial hacia las partes altas de Jicamarca que siguen olvidadas; por su parte la nueva población foránea tiene como objetivo la ocupación legal de sus viviendas, con dotación de servicios básicos para los mismos. Pero a pesar de esta situación los dirigentes de estos nuevos anexos no renuncian a desmembrarse de la comunidad ya que, si lo hacen, perderían todos sus derechos como comuneros; sin embargo, a la mayoría de la población que integra estos anexos no le interesa la comunidad (Gutiérrez Galindo 1998).

\subsection{Rol y responsabilidad de los entes competentes en la ocupación del territorio}

De acuerdo con la Ley Orgánica de Municipalidades N. 27972 vigente, en el artículo 79, referido a la organización del espacio físico, inciso 1.1 y 1.2, se menciona como función específica de las municipalidades provinciales, aprobar su plan de acondicionamiento territorial a nivel provincial, así como aprobar su plan urbano, el inciso 1.4 .3 señala que es función exclusiva a nivel provincial el reconocimiento, verificación, titulación y saneamiento físico legal de asentamientos humanos; el mismo artículo inciso 3.1 señala también como función exclusiva de las municipalidades distritales, aprobar su plan urbano o rural distrital según corresponda. Tal como menciona esta norma la planificación territorial, con la finalidad de que la ocupación del territorio sea de manera ordenada y planificada, es competencia de las municipalidades provinciales y distritales en el Perú. Si bien es cierto que el crecimiento urbano más expansivo de Chosica se inicia desde la década de los 70 , cuando aún no estaba 
vigente esta norma; la ley orgánica de municipalidades de 1984, estipulaba la competencia del gobierno local en esta materia. Sin embargo, la ocupación del territorio se ha realizado sin ningún criterio de planificación, carentes de instrumentos de ordenación del territorio; como consecuencia la ciudad se ha expandido de manera desordenada e informal, en su mayoría mediante invasiones y en algunos casos a través del tráfico de terrenos incluso con la anuencia de las autoridades.

En la actualidad en Chosica se ha determinado la existencia de 27 zonas y alrededor de $30 \mathrm{mil}$ familias en nivel de riesgo alto, muchas de las viviendas ubicadas en zonas altamente vulnerables han sido legalizadas, ya que cuentan con título de propiedad otorgado por la entidad pública competente en la formalización de la propiedad; asimimo, hay edificaciones que han sido construidas con permiso municipal, tal como manifiestan los propios pobladores.

Además se ha constatado, en el área de estudio, la existencia de indefiniciones limítrofes entre el distrito de Lurigancho-Chosica y el distrito de San Antonio. La ley de creación del primero es muy genérica que no hace mención a los límites del distrito; por otra parte, en el caso del distrito de San Antonio su creación se dio por Ley N. ${ }^{\circ} 10161$ en 1944, en la cual menciona que el distrito estará formado por los pueblos de Chaclla, Jicamarca, Collata y Vicas y sus límites serán los de la línea de contorno del conjunto de dichos pueblos. De manera que la interpretación sobre definición de límites de ambos distritos es contradictoria, para San Antonio coinciden con los límites de la comunidad de Jicamarca, tomando como referencia una acequia que se extiende desde Santa Eulalia que bordea la margen derecha del río Rímac hasta San Juan de Lurigancho, es decir se extiende más allá de la divisoria de aguas y donde estarían comprendidos varios asentamientos poblacionales ubicados en la margen derecha del río Rímac, como es el caso de Nicolás de Piérola, San Antonio de Pedregal, Carossio, entre otros. En cambio, para el distrito de Lurigancho-Chosica los límites están definidos por la divisoria de aguas, por consiguiente los asentamientos poblacionales mencionados anteriormente estarían comprendidos dentro de este distrito.
Por otro lado, un sector considerable de las tierras ubicadas en el área de estudio forman parte de la comunidad de Jicamarca que cuenta con 24 anexos, 4 de estos anexos, como Víctor del Carmen la Era, Las Tunas, Anexo 22 Pampa Canto Grande y Nicolás de Piérola, forman parte de la administración del centro poblado Nicolás de Piérola, que a su vez depende política y administrativamente del distrito de San Antonio.

La presencia de dos circunscripciones en disputa genera un problema social y político cuyo principal afectado es la población que ocupa este territorio; las discrepancias son continuas entre los dos distritos. Por un lado, hay poco apoyo a la municipalidad del centro poblado Nicolás Piérola por parte de la propia municipalidad de San Antonio; y, por otra parte, la actual autoridad local de LuriganchoChosica, cuyo período se extiende por 25 años ininterrumpidos, no presta el apoyo a estos asentamientos poblacionales, por el contrario, se ha promovido la creación de más asentamientos poblacionales otorgándoles reconocimientos legales a los mismos, pero carentes de servicios básicos elementales. Esta situación genera conflictos entre los asentamientos poblacionales, que tarda o bloquea las obras, proyectos y servicios que requiere la población, tal como nos hicieron saber las autoridades del centro poblado Nicolás de Piérola. Un caso específico que podría graficar esta situación problemática es el asentamiento poblacional denominado el Vallecito, ubicado en la margen derecha del río Rímac frente a Chaclacayo, que ha sido fuertemente afectado por El Nińo Costero 2017, debido a que en la parte alta una nueva invasión poblacional promovida desde Chosica ocupó el cauce de la quebrada, lo que provocó la acumulación de material y luego, ante la activación del torrente, rompió el dique arrasando la parte baja del poblado de Vallecito. Este poblado, a pesar de su cercanía con la parte baja de Chosica y Chaclacayo, carece de todos los servicios básicos elementales como agua y luz, en suma, la población se encuentra olvidada por las autoridades. Así, según manifiestan los dirigentes comunales de Vallecito y Yanacoto, el 80\% de niños se encuentran con anemia, además de padecer de infección urinaria, expuestos ante la carencia de agua potable y servicios médicos elementales. 


\section{Respuesta del Estado ante el evento "El Niño Costero 2017»}

Finalmente, la ocurrencia de «El Niño Costero 2017» ha puesto de manifiesto las responsabilidades confusas existentes entre los tres niveles de gobierno, falta de coordinación, improvisación, etc. Existen leyes y políticas a nivel nacional que regulan la gestión de riesgo de desastres (GRD); existen entidades nacionales restructuradas recientemente como es el caso del Sistema Nacional de Gestión de Riesgos de Desastres (SINAGERD) desde diciembre de 2016, donde el Ministerio de Defensa (MINDEF) fue asignado por decreto para liderar las emergencias, el Instituto de Defensa Civil (INDECI) y el Centro Nacional de Prevención de Riesgos (CENEPRED), que con todas sus funciones, excepto una, fueron trasladadas por decreto al MINDEF, que pasó a liderar las emergencias desde el 24 de febrero de 2017, justo antes de la ocurrencia de «El Niño Costero». El Ministerio de Vivienda, Construcción y Saneamiento (MVCS) asumió la responsabilidad de las inspecciones técnicas que eran antes de incumbencia del CENEPRED. De manera que el liderazgo ha quedado fragmentado y las líneas de autoridad no son claras. El CENEPRED e INDECI, que alguna vez estuvieron en el mismo nivel de un ministerio, se encuentran ahora degradados. Además, mayores responsabilidades en la GRD fueron asignadas a los ministerios sectoriales (Venkateswaran, MacClune, Enríquez 2017).

A nivel subnacional el gobierno regional debe supervisar e implementar programas regionales, además de ser el enlace entre el gobierno nacional y los gobiernos regionales y locales, brindar apoyo técnico a los gobiernos locales para implementar políticas nacionales y requisitos para preparación y gestión de riesgo de desastres a través de los Centros Regionales de Operaciones de Emergencia (COER). Sin embargo, lo que más ha primado es la descoordinación entre el gobierno regional y local. El gobierno local es el primer nivel que da respuesta a emergencias durante desastres a través de los Grupos de Defensa Civil municipal y los Centros de Operaciones de Emergencia (COE). Deberían contar con Centros de Operación Local de Emergencias para vigilar y dirigir la respuesta. Pero estas entidades no funcionan en muchos gobiernos locales, por lo que su actuación fue muy restringida (Venkateswaran, MacClune, Enríquez 2017).

En el caso de Chosica, la municipalidad distrital se dedicó a la construcción de muros de contención en las márgenes del río Rímac, como es el caso del asentamiento Canta Gallo, ubicado en la misma ciudad de Chosica, esta obra fue criticada por el retraso y la infraestructura utilizada en su construcción. Se ha podido constatar que la respuesta del Estado es displicente y en el mejor de los casos es lenta en la ejecución de medidas de prevención, construcción y rehabilitación de la infraestructura afectada en las zonas de alto riesgo ocupadas por la población.

Lo que podemos rescatar es que el ańo 2015 previniendo la ocurrencia del fenómeno de El Niño 2016, que no ocurrió, el gobierno central, a través de la Autoridad Nacional del Agua (ANA), puso en ejecución la construcción de 20 geomallas de origen suizo con la finalidad de disminuir los efectos destructivos de los huaicos, su función fue la retención del material rocoso de mayor espesor que transporta el huaico. Estas fueron instaladas a lo largo de las quebradas principales, como Quirio, Pedregal, Carosio y otras; lo que permitió disminuir los efectos destructivos ante la ocurrencia del fenómeno. Sin embargo, después de la ocurrencia del evento estas han quedado colmatadas por enormes cantidades de material rocoso, lo cual requiere su limpieza y mantenimiento.

La acción de los entes competentes ante la ocurrencia del fenómeno debe darse en tres situaciones temporales: el antes, el durante y el después. Con énfasis en la prevención en la parte alta, en la zona de recepción, donde se debe promover la presencia de vegetación que sirva como colchón receptor y distribuidor natural del agua a largo plazo; en la parte media las propuestas de actuación deben darse a través de la construcción y mantenimiento de geomallas y reconstrucción de diques para retener la velocidad del torrente y el material más grueso. Luego, en la parte media y baja donde está asentada la población, se debería actuar de dos maneras, una mediante la capacitación constante a la población en temas relacionados a mejorar su organización, sistema de alerta temprana, gestión de riesgo, entre otros; la finalidad es mejorar la resiliencia ante la ocurrencia de un evento. Por otro lado, se deben prohibir las construcciones de viviendas en zonas altamente 
vulnerables como el cauce de las quebradas, y con las que actualmente están ocupando esta zona se deben hacer todos los esfuerzos para ser reubicadas en otros lugares más seguros.

\section{Conclusiones y recomendaciones}

- La ocurrencia de «El Niño Costero 2017» ha significado una violenta e inusual manifestación climática en la costa peruana; el ENFEN lo define como la elevación anómala y persistente de forma abrupta de la temperatura superficial del mar en el Océano Pacífico adyacente a la costa del norte del Perú y de Ecuador.

- Los efectos de la ocurrencia del fenómeno de «El Niño Costero 2017» genera mayores desastres cuando los emplazamientos poblacionales están ubicados en zonas con alto nivel de vulnerabilidad, situación que ha desbordado la respuesta del Estado para una ocupación ordenada y planificada.

- Las condiciones de ocupación son extremadamente precarias en algunos sectores, principalmente los que ocupan las áreas marginales y periféricas carentes de servicios básicos, pero que cuentan con títulos de propiedad.

- Los conflictos limítrofes están presentes entre los distritos de Lurigancho-Chosica y San Antonio, que afecta la cohesión organizacional de los asentamientos poblacionales inmersos en este ámbito.

- La respuesta del Estado es inexistente y en algunos casos lenta para la ejecución de medidas de prevención, construcción y rehabilitación de la infraestructura afectada en las zonas de alto riesgo del río, quebradas y laderas.

- Las áreas ocupadas por la población donde han edificado sus viviendas, definidas como zonas de alto riesgo, al aplicar las encuestas manifiestan su deseo de ser reubicados; adicionalmente se constató que no existe ningún nivel de resiliencia en la población para desarrollar acciones en caso de ocurrencia de fenómenos naturales.

- Las acciones del Estado deben darse de manera coordinada entre los tres niveles de gobierno: en el antes, el durante y el después de la ocurrencia del fenómeno.
- Conviene desarrollar tareas de prevención sostenibles en la zona de captación, donde se produce el aporte de material sólido e hídrico, con el objetivo de regular la escorrentía hídrica desde sus orígenes; fomentar la reforestación de especies vegetales nativas de la zona que sirva como colchón receptor y regulador a largo plazo.

- La labor de prevención se debe orientar al reforzamiento y mantenimiento de geomallas para retener la velocidad del torrente, asimismo la descolmatación y reconstrucción de diques cuya función es disminuir la velocidad.

- Se debe elaborar un proyecto integral de desarrollo urbanístico que involucre intervenciones con relación al ordenamiento y la ocupación territorial y ambiental, la zonificación y usos del suelo.

- Los entes competentes tanto del gobierno central como local deben ejecutar programas de capacitaciones para la población dirigidos a mejorar la resiliencia y prevención de riesgos, ante eventos naturales y antrópicos.

- Mediante acuerdo las municipalidades distritales de Chosica-Lurigancho y San Antonio, deberían hacer una propuesta de saneamiento de sus límites.

- Se debe prohibir las construcciones de viviendas en zonas altamente vulnerables como el cauce del río y las quebradas, márgenes adyacentes y laderas de altas pendientes; por otro lado, las viviendas que actualmente ocupan estas zonas deben de ser reubicadas en otros lugares más seguros.

\section{Agradecimientos}

Expresamos nuestro reconocimiento al grupo de investigación "Geo Estudios Territoriales» de la UNMSM en donde se gestó esta investigación; especialmente el apoyo de Elmer Alberto Ccente Pineda, Víctor Giudice Baca, Roselyn Chacón Gonzales, Keidy Dávila Retamozo, Mac Felipe Tovar, Jennrry Romo Chinchón, Sayda Ramos Pallarco, Renee Rojas Ayala, Gianina Comeca Ramírez, Jacqueline Meza Quispe, Gloria Martínez Taipe, Kimberly Bendezú Gala, José Rasmussen de la Cruz. También agradecemos a las autoridades de la Municipalidad del Centro Poblado Nicolás de Piérola por su apoyo. 


\section{Bibliografía}

AвAd Pérez, César (2009). Bulletin de l'InstitutFrançaisd'É tudesAndines, 38 (3): 475-486.

Cáceres Heredia, José; La Torre Ruiz, Fabriciano; Ccente Pineda, Elmer (2005). Propuesta de delimitación territorial del distrito de San Antonio. Provincia de Huarochiri-Dpto. Lima.

Chang Huayanca, Antonio (2014). La cobertura periodistica del fenómeno del niño de 1925-1926 en el diario El Comercio de Lima. Tesis.

ENFEN (2017). Informe Técnico Extraordinario N. ${ }^{\circ} 001-$ 2017. El Niño Costero.

Gutiérrez Galindo, Blas (1998). Jicamarca. Descontrol de su territorio comunal. Año 2 N. ${ }^{\circ}$, pp. 9-24. UNMSMIIHS. Lima.

INDECI (2012). La gestión del riesgo de desastres en el Perú. Documento país.
Instituto Geofísico del Perú (2017). Generación de modelos climáticos del fenómeno del niño. Lima.

Ministerio De Agricultura. Evaluación de los recursos hidricos de la cuenca del río Rimac. Informe de la Dirección de Conservación y Planeamiento de recursos hídricos.

O’Connor Salmón, Hugo (1989). Investigación del huayco de Chosica 1987, sus efectos y medidas de mitigación. Tesis UNI.

Plan de Desarrollo Local Concertado Distrital de Lurigancho-Chosica. 2013-2025.

Rocha Felices, Arturo. El impacto del fenómeno del niño en las zonas urbanas.

SENAMHI. Fenómeno del niño en el Perú.

Venkateswaran, K., MacClune, K. y Enríquez, M.F. (2017). El Niño Costero: The 2017 Floods in Perú. Zurich Flood Resilience Alliance. 